\title{
Investigation of the Flow Characteristics of Titanium - Oxide - Water Nanofluid in Microchannel with Circular Cross Section
}

\author{
Saleh Etaig ${ }^{1, ~ *, ~ R e a z ~ H a s a n ~}{ }^{2}$, Noel Perera ${ }^{2}$ \\ ${ }^{1}$ Mechanical Engineering Department, University of Benghazi, Benghazi, Libya \\ ${ }^{2}$ Mechanical Engineering Department, Northumbria University, Newcastle, UK
}

Email address:

Etaig.Mahmoud@Northumbria.ac.uk (S. Etaig)

*Corresponding author

\section{To cite this article:}

Saleh Etaig, Reaz Hasan, Noel Perera. Investigation of the Flow Characteristics of Titanium - Oxide - Water Nanofluid in Microchannel with Circular Cross Section. American Journal of Nano Research and Applications. Vol. 5, No. 6, 2017, pp. 102-109.

doi: 10.11648/j.nano.20170506.14

Received: October 18, 2017; Accepted: October 31, 2017; Published: December 22, 2017

\begin{abstract}
The presented paper reports the analysis of the flows characteristic of $\mathrm{TiO}_{2}$-water nanofluid flowing inside a horizontal microchannel with circular cross section area. The flow is investigated by CFD techniques using a finite volume method. A recently introduced viscosity correlation was used to model the effective viscosity of the nanofluid. A range of Re number is tested in the present study. Various temperature ranges were used as constant temperature boundary conditions. The increase of the nanoparticle volume fraction was found to increase the heat transfer rate; water showed less enhancement in heat transfer compared to the nanofluid. The increase in Re number promoted Nu number. The effect of the temperature on the effective viscosity in the channel was also reported. The change of the velocity in the entrance region was studied and discussed. The velocity gradient in the microchannel is calculated, and the results are shown and discussed.
\end{abstract}

Keywords: Nanofluid, Convection, Viscosity and Microchannel

\section{Introduction}

The substantial developments in electronics, power stations, optical devices, transportation and many other applications lead to an increased need for high heat flux dissipation. Such applications can be micro-heat exchangers, micro-heat sink, micro-nozzle, and micro-reactor. These devices have many advantages; one of which is their larger component parts. The most superior feature of micro-heat exchangers is their ability to work with close approach temperatures, which provides high effectiveness. Their features can be summarized as:

a High surface area per volume ratios.

b High heat transfer coefficients.

c Low thermal resistances.

In the last two decades, the nanofluids have been investigated in many industrial applications due to their

exceptional thermophysical properties in comparison to the conventional fluids such as water which inherently has limited thermal conductivity. Since Choi [1] first introduced the nanofluid concept, many researchers investigated the nanofluid enhancement in various applications. The microchannel heat sink attracted many researchers due to their properties and demanding applications. Koo et al. [2] studied the laminar flow in microchannel heat pipe and their aspect ratio; they found that the channel with high aspect ratio is desirable. Chevallier et al. [3] investigated the rheological properties of nanofluid flowing in the microchannel.

Nguyen et al. [4] investigated the laminar flow in microchannel using single and two-phase models. The results revealed that the wall heat transfer coefficient enhanced with the increase in Re number and the increase in the volume fraction. Jie et al. [5] studied the entropy generation in a microchannel; they highlighted that the friction factor entropy generation becomes more important with the increase in the inlet velocity.

Walchli et al. [6] tested the microchannel performance 
cooling. They proposed to limit the complexity of a threedimensional CFD model to the modeling of only the unit cell of the heat exchanging meshes in microchannels.

Kalteh et al. [7] conducted an experimental and numerical study to investigate the heat transfer performance in microchannels. They found that the nanofluid can be considered as a homogeneous mixture and the velocity and temperature profiles for two-phase results are flatter than the base water or homogeneous model profiles.

Mohammed et al. [8] highlighted the deviations in some results in experimental and numerical results in microchannel applications using nanofluids. Vivekanand et al. [9] studied the evaporation heat transfer in a rectangular microchannel. They showed that the vapor volume fraction varies substantially when the heat flux boundary condition is applied at the wall. Chein and Huang [10] investigated the heat performance of $\mathrm{Cu}$-water nanofluid in a microchannel. They highlighted that the heat performances significantly improved due to the augmentation in the thermal conductivity. However adding nanoparticles to the base fluid showed no penalty in the pressure drop. The cooling performance of the nanofluid in a microchannel heat sink was studied numerically by Jang and Choi [11]. The results showed that the cooling heat transfer is enhanced by up to $10 \%$ compared with water base fluid.

Chein and Chuang [12] investigated theoretically and experimentally the heat performance for cuo-water nanofluid in microchannel heat sink. They reported that nanofluid absorbed more energy than water-base fluid at low flow rate. At higher flow rates, the increase in nanoparticles did not show any further heat absorption. The observed wall temperature variations were in agreement with the theoretical calculations at low flow rate. However, at a higher flow rate, the measured wall temperatures were in discrepancy with the theoretical calculations. Only marginal increase in pressure drop due to the presence of nanoparticles was detected.

The effect of the height of the microchannel and the volume concentration on the heat transfer performance was investigated experimentally by Manay and Sahin [13] for $\mathrm{TiO}_{2}$-water nanofluid under constant heat flux. Four different heights were tested $(200,300,400$ and $500 \mu \mathrm{m})$ for various volume fractions. They observed an improvement in the heat transfer for all volume concentrations tested. However, no enhancement was reported for volume concentrations greater than $2 \%$. The decrease in the microchannel height increased the heat transfer under constant width. Among the microchannel heights tested, the channel with height $200 \mu \mathrm{m}$ showed the highest heat transfer rate. On the other hand, an increase of $10-50 \%$ in the friction factor was reported when decreasing the microchannel height from 500 to $200 \mu \mathrm{m}$.

An experimental investigation on the enhancement of $\mathrm{Al}_{2} \mathrm{O}_{3}$-water nanofluid in a microchannel was investigated by Lee and Mudawar [14]. The augmentation in the thermal conductivity enhanced the heat single-phase transfer. However, this enhancement was observed on the laminar flow only, when in the turbulent flow insignificant enhancement was observed. They attributed this weak enhancement to the lack of dependence of the heat transfer on the thermophysical properties in the turbulent region. The water-based fluid showed less heat transfer compared to the nanofluid. However, the enhancement in the heat transfer was observed in the entrance region only, where in the fully developed region they reported an insignificant heat transfer improvement.

Byrne et al. [15] conducted an experimental investigation on the thermal performance of $\mathrm{CuO}$-water nanofluid in a rectangular microchannel. An increase in the heat transfer rate of up to $17 \%$ was observed at a volume concentration of $0.01 \%$. However, insignificant increase in the pumping power was reported. They suggested that using the surfactants is crucial for homogenous dispersion of the nanoparticles in the fluid. Hung et al. [16] presented a numerical study on the enhancing of the heat transfer for various nanofluids in a microchannel. The highest heat transfer predicted in their study was achieved when using $\mathrm{Al}_{2} \mathrm{O}_{3}$-water nanofluid of about $21.6 \%$ compared to the water base fluid. Their predictions showed that when the volume fraction increased, the thermal resistance decreased and then increased. According to their simulations, the heat transfer improved with the decrease in the nanoparticle diameter.

Jung et al. [17] investigated experimentally the convective heat transfer performance for $\mathrm{Al}_{2} \mathrm{O} 3$-water nanofluid in a microchannel. Their measurement for the heat transfer coefficient in the laminar regime showed an increase up to $32 \%$ in comparison to the water base fluid. The Nusselt number showed measured increases with increasing the Reynolds number in the laminar flow regime. However, their results for $\mathrm{Nu}$ number are not in agreement with the conventional correlations calculations.

The heat transfer enhancement in a microchannel for $\mathrm{SiO}_{2}-$ water nanofluid was investigated experimentally by Anoop et al. [18]. The measured viscosity was enhanced up to $7 \%$; the heat transfer deteriorated when the nanofluid flow rate increased beyond a critical value. Before the critical value, the heat transfer was improved. Tokit et al [19] investigated the heat transfer and the fluid flow for three different nanofluids in a rectangular microchannel. The highest augmentation in the thermal conductivity among the different nanofluids was $1.18 \%$ for $\mathrm{Al}_{2} \mathrm{O} 3$. However the relative $\mathrm{Nu}$ number $N u_{n f} / N u_{w}$ improvement was $2.67 \%$.

A three-dimensional numerical study on the thermal performance in a microchannel with double layer was presented by Hung and Yan [20] for $\mathrm{Al}_{2} \mathrm{O} 3$-water nanofluid. Their predictions revealed that the maximum enhancement in the microchannel could be achieved when $\mathrm{Al}_{2} \mathrm{O} 3$-water nanofluid was used. The thermal resistance was reduced by correctly altering the volume concentration under different pumping powers. Furthermore, the minimum thermal resistance can be affected by the geometric parameters. They reported that the thermal performance could be enhanced by increasing the width ratio of the microchannel or decreasing channel aspect ratio. At a given pumping power an enhancement in the thermal performance was $26 \%$ at a volume fraction at $1 \%$ over that of pure water. 
Malvandi et al. [21] investigated theoretically the migration of the nanoparticle influence on the convective heat transfer in a vertical microchannel for $\mathrm{Al}_{2} \mathrm{O} 3$-water nanofluid. They revealed that the effect of the temperaturedependent buoyancy is minor; however, a significant effect of the concentration-dependent buoyancy on flow and heat transfer characteristics was reported. Malvandi et al. [22] presented a theoretical study on the nanoparticle migration effect on the fully developed flow under laminar region using $\mathrm{Al}_{2} \mathrm{O} 3-$ water in a microchannel. They reported that the buoyancy effect was improved; however, there was an acceleration in the velocity near the walls, where there was no acceleration in the velocity in the core. They reported that the buoyancy influence had a negative impact on the cooling performance. This negative effect significantly depends on the nanoparticle diameter.

Zhang et al [23] conducted an experimental investigation to study the heat transfer and flow characteristics of $\mathrm{TiO}_{2}-$ water nanofluids in a multiport minichannel tube. They highlighted that $0.01 \%$ was the optimal nanofluids volume fraction and its enhancement of heat transfer being $61 \%$ at the Re number 6100

Different configurations of microchannels were investigated by several researchers. Kuppusamy et al. [24] studied the geometrical parameters for four different nanofluids in a trapezoidal microchannel. Their predictions revealed that the increase in the maximum width and the decrease in the minimum width of the trapezoidal demonstrated the highest thermal performance; this suggested that the triangular cross section would be recommended in comparison to the rectangular cross section microchannels.

The heat transfer enhancement in a Serpentine Shaped microchannel was experimentally investigated by Sivakumar et al. [25]. Four different configurations were tested using $\mathrm{Al}_{2} \mathrm{O} 3$-water for volume concentrations up to $0.1 \%$. They highlighted that the pressure drop increased with the decrease in the microchannel hydraulic diameter. Furthermore, the heat transfer improvement is a function of the hydraulic diameter and the microchannel dimensions.

The present work aims to investigate the enhancement of heat transfer rate in a microchannel with $\mathrm{TiO}_{2}$-water nanofluid flowing inside with a circular cross section subjected to a constant temperature boundary condition on the wall.

\section{Problem Description}

The geometry considered in this study is shown in Figure 1 , a microchannel with length $4 \mathrm{~cm}$ and a diameter $106 \mu \mathrm{m}$ with constant external temperature. The nanofluid enters the pipe with temperature $T_{0}=300 \mathrm{~K}$ and uniform axial inlet velocity. At the pipe exit, a fully developed flow condition is considered. The fluid considered in this study is $\mathrm{TiO}_{2}$-water nanofluid. The properties of the nanoparticles are shown in Table 1.

Table 1. Nanoparticle thermophysical properties.

\begin{tabular}{|c|c|c|c|}
\hline Nanoparticle & Density $\mathrm{Kg} / \mathrm{m}^{3}$ & 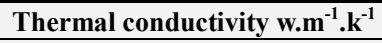 & Specific heat $\mathrm{J} \mathrm{kg}^{-1} \cdot \mathrm{k}^{-1}$ \\
\hline $\mathrm{TiO}_{2}$ & 4250 & 8.93 & 686.2 \\
\hline
\end{tabular}

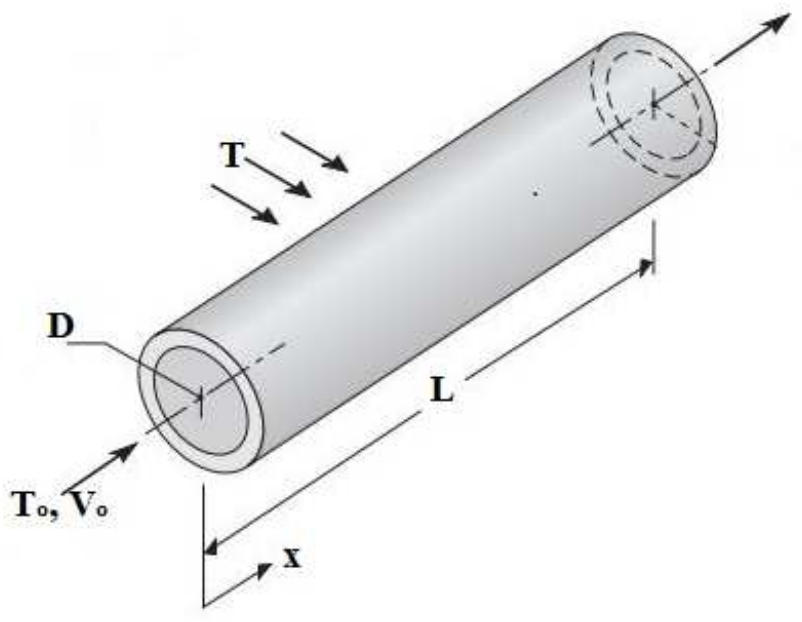

Figure 1. Geometry of the microchannel.

\section{Governing Equations and Thermophysical Properties of Nanofluid}

The governing equations solved in the present study are the continuity equation, momentum equation, and energy equation. The continuity equation can be written as:

$$
\nabla(\rho \vec{v})=0
$$

The momentum equation is expressed as:

$$
\nabla(\rho \vec{v}) \vec{v}=-\nabla p+\nabla(\tau)+\rho g+F
$$

The energy equation can be written as:

$$
\nabla(\vec{v}(\rho E+P))=\nabla\left(K_{e f f} \nabla T-\sum h_{j} J_{j}+(\tau \vec{v})\right.
$$

The thermophysical properties for the nanofluid are expressed as a function of the volume fraction, nanoparticle properties and the thermophysical properties of the base fluid which is water in the present study.

The nanofluid density is written as:

$$
\rho_{n f}=(1-\phi) \rho_{f}+\emptyset \rho_{s}
$$

The specific heat of the nanofluid is expressed as:

$$
C_{p n f}=\frac{(1-\varphi)\left(\rho C_{p}\right)_{f}+\varphi\left(\rho C_{p}\right)_{s}}{\rho_{n f}}
$$

The thermal conductivity can be calculated as: 


$$
K_{e f f}=K_{f}\left(\frac{K_{S}+2 K_{f}-2 \emptyset\left(K_{f}-k_{S}\right)}{K_{S}+2 K_{f}+\emptyset\left(K_{f}-k_{S}\right)}\right)
$$

The effective viscosity is written as [26]:

$$
\mu_{e f f}=\mu_{f}\left(1+5 \emptyset+80 \emptyset^{2}+160 \emptyset^{3}\right)
$$

The heat transfer coefficient can be written as:

$$
h=\frac{Q}{\left(T_{H}-T_{C}\right)}
$$

$\mathrm{Nu}$ number is calculated as:

$$
N u=\frac{h L}{k}
$$

Re number is expressed as:

$$
R e=\frac{U D \rho}{\mu}
$$

\section{Numerical Procedure}

The governing equations (1), (2) and (3) were solved with the boundary conditions numerically using ANSYS 15.0 [27]. The computational domain was discretized in ANSYS meshing, and the governing equations were solved together with the boundary conditions in ANSYS FLUENT. The CFD code is based on the finite volume method and SIMPLE algorithm that solves the governing equations. The approach is well known for the solution stability. Second-order upwind schemes were used for the convective fluxes. Convergence was achieved with residuals less than $10^{-6}$ for all governing equations.

\subsection{Mesh dependency Test}

To ensure the solution is mesh independent, the maximum $\mathrm{Nu}$ number at the outer surface was used. The solution is chosen to be mesh independent when the percentage change in maximum $\mathrm{Nu}$ remained less than $1 \%$ to provide a meshindependent predictions for all simulations in the present investigation. Table 2 shows the mesh dependency test for maximum $\mathrm{Nu}$ and it is clearly seen that for the mesh with 1015454 elements the maximum $\mathrm{Nu}$ becomes insensitive to any further refinement and therefore the mesh was selected for the solution.

Table 2. Mesh dependency test.

\begin{tabular}{lll}
\hline Mesh & No. of Elements & $\mathbf{N u}_{\max }$ \\
\hline 1 & 926408 & 113.26 \\
2 & 1010200 & 116.65 \\
3 & 1015454 & 119 \\
4 & 1020040 & 119.24 \\
\hline
\end{tabular}

\subsection{Results Validations}

The computational model is first validated with the numerical and experimental data from Lee [28]. The volume fraction in equations (4-7) goes to zero. The results are shown in Figure 2. The graph shown represents the relation between $\mathrm{Re}$ number and $\mathrm{Nu}$ number. As the $\mathrm{Re}$ number increases, the Nu number increase. It can be clearly seen the present predictions agree well with the numerical and experimental work by Lee. The results of the present investigations are presented in the next section.

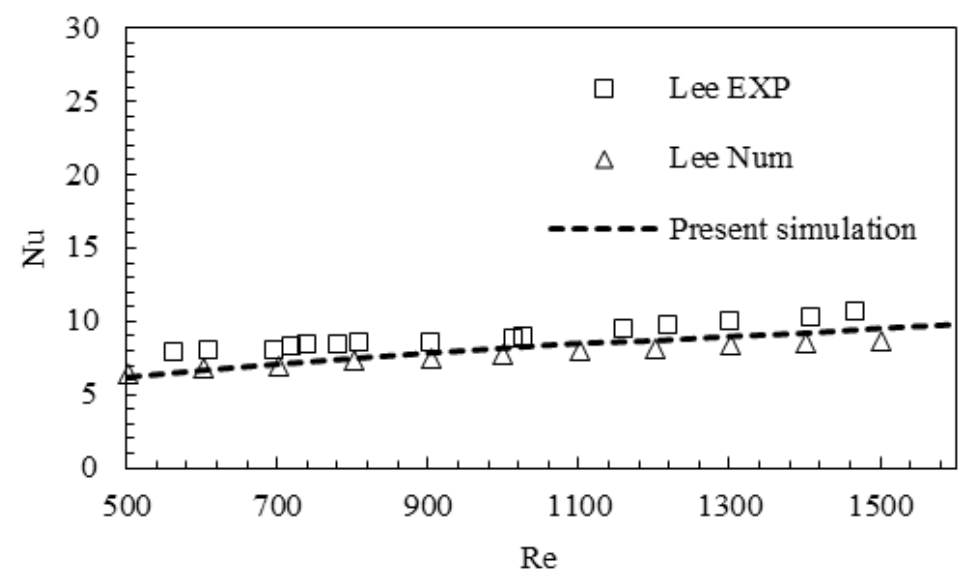

Figure 2. Results validations.

\section{Results and Discussions}

The numerical simulations were performed, and the results and the discussions are presented in this section.

The change of the velocity profile in the entrance region is investigated, the results are shown in Figure 3. The graph depicts the $u$ velocity profile at a different distance from the microchannel inlet. The profile of the velocity is tested at 0.8 $\mathrm{mm}, 4 \mathrm{~mm}, 9 \mathrm{~mm}$ and $20 \mathrm{~mm}$ from the entrance region. The $\mathrm{y}$-axis represents the $\mathrm{u}$ velocity and $\mathrm{x}$ axis represents a vertical line in the microchannel entrance at a certain distance as shown in the Figure 3 . The change of the velocity at the end of the entrance region is a parabola, at that point, the flow is fully developed, and there is no change in the velocity with time, i.e., the velocity becomes constant at that point onward. However the velocity at $\mathrm{x}=0.8 \mathrm{~mm}$ from the entrance shows the minimum velocity, which is resulted from the inlet boundary conditions. The more the flow departs from the inlet, the more the magnitude of the velocity until the flow becomes fully developed 


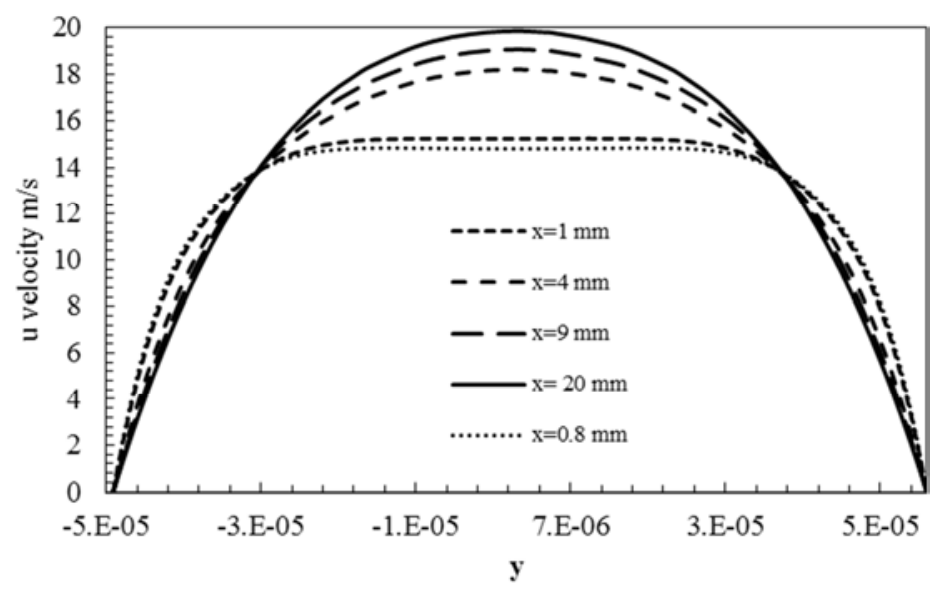

Figure 3. Velocity change in the entrance region.

The viscosity change in the entrance region was also investigated. The understanding of the viscosity change in the microchannels is essential as the viscous dissipation is reported several times in the literature. The change of the viscosity is illustrated in Figure 4. As the viscosity decreases with the increase in the temperature, so it is anticipated that the viscosity has the maximum value in the entrance of the microchannel. The viscosity is calculated at various distances from the entrance ranging from $0.5 \mathrm{~mm}$ to $20 \mathrm{~mm}$ where the temperature is constant from that point towards the $\mathrm{x}$-axis of the channel. The reason for this is attributed to the increase in the temperature as a result of the external constant temperature whish was assumed as an external boundary condition. The vertical line where the viscosity predicted is located at the diameter of the microchannel. By looking at the constant viscosity at a distance $0.5 \mathrm{~mm}$ at the vertical line along the y-axis, this constant value changes suddenly at the near wall region of the microchannel. This sudden change is a result of the viscous layer which has the maximum value near the wall. Again the viscosity is a function of the temperature so, by increasing the temperature when the flow enters the microchannel, the viscosity will decrease.

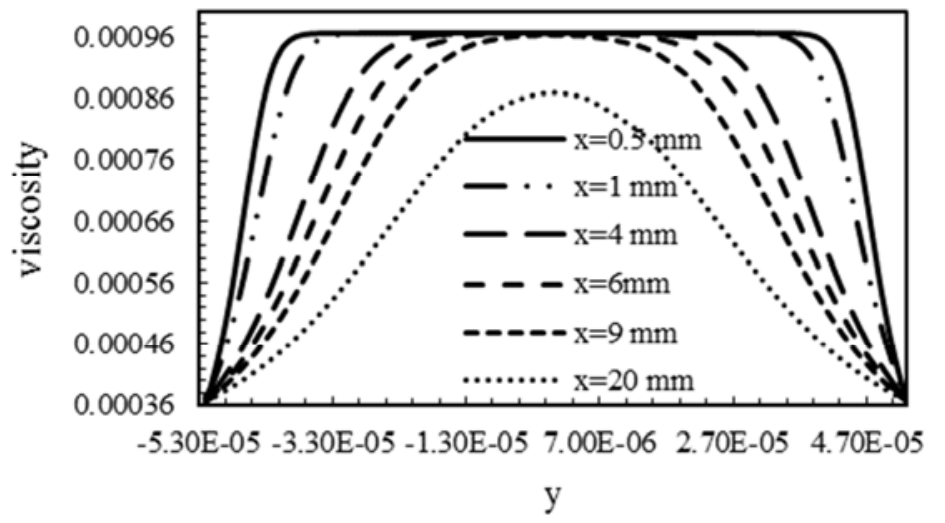

Figure 4. Viscosity change in the entrance of the microchannel.

In order to investigate the heat transfer enhancement, $\mathrm{Nu}$ predictions were also studied. The calculations of $\mathrm{Nu}$ for various volume fractions are shown in Figure 5. The range of volume concentrations tested in the present investigations ranges from $2 \%$ to $6 \%$ as well as water. It is found that $\mathrm{Nu}$ begins with a maximum value and decreases along the microchannel wall where it remains unchanged. Also from Figure 5, the effect of the the volume fraction on the $\mathrm{Nu}$ was found in favor of the heat transfer rate. The increase in the volume fraction significantly improved the heat transfer. The weakest heat performance was shown in the case of water working fluid. The reason behind the promoted heat transfer rate as the volume fraction increases is the augmentation in the thermal conductivity due to the presence of the nanoparticles in the fluid. As the thermal conductivity of the working fluid increased rapidly, the nanofluid demonstrated an improvement in the heat transfer.

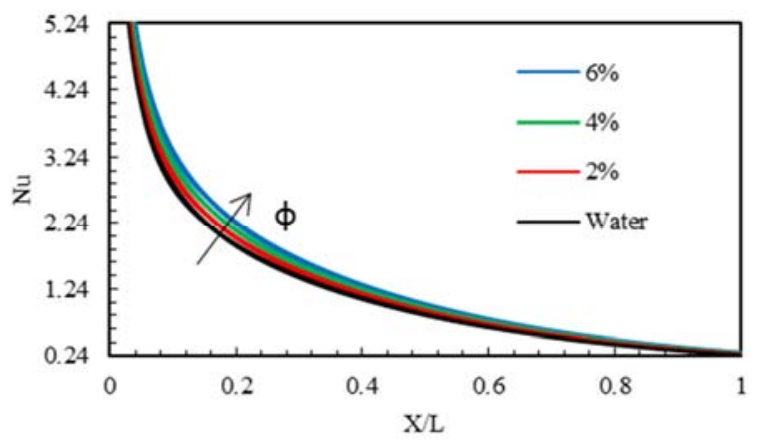

Figure 5. The effect of volume fraction on Nu along the microchannel. 
The drop in the pressure is also investigated for several Re numbers. The understanding of this change is crucial for optimum pump design. The change in the pressure along the microchannel for different Re numbers is shown in Figure 6. The range of Re number was from 200 to 1800 . The pressure declined along with the microchannel where at the end of the channel zero gauge pressure was assumed. It can be seen that the increase in the Re number will result in the increase in the pressure. This has a negative impact on the pump power. On the other hand, it is that increase in the Re number which promotes the heat transfer.

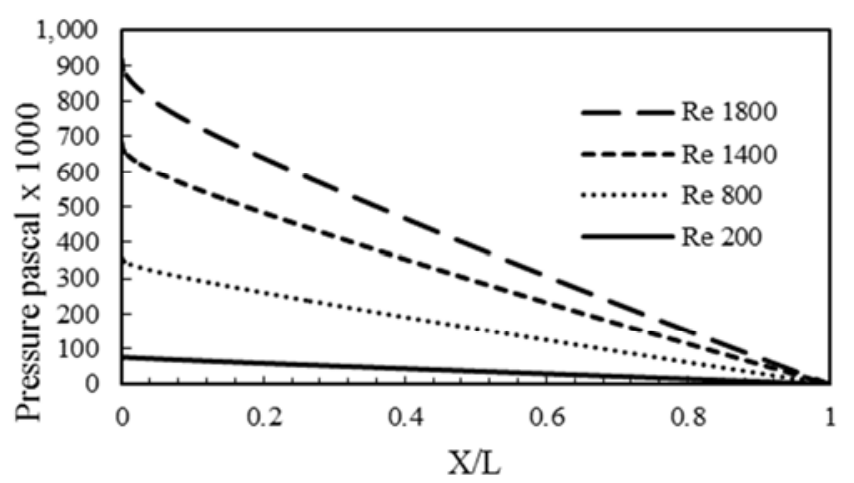

Figure 6. The pressure drop in the microchannel.

The change of the Temperature in the microchannel was also studied in the entrance region. The temperature variation at certain distances is shown in Figure 7. The temperature has the minimum value at the entrance where the fluid enters the microchannel with constant temperature $300 \mathrm{~K}^{\circ}$. As a result of the heat transfer, the temperature of the fluid increased gradually with the $\mathrm{x}$-axis until the flow becomes fully developed where the temperature remained unchanged. At $\mathrm{x}=0.5 \mathrm{~mm}$ the temperature has the lowest value $\left(300 \mathrm{~K}^{\circ}\right)$ which is the same temperature of the inlet boundary condition. At $X=20 \mathrm{~mm}$ the temperature increased to the maximum value at the center line of the microchannel.

The effect of the hydraulic diameter of the microchannel on the heat transfer rate was also investigated and the results are shown in Figure.

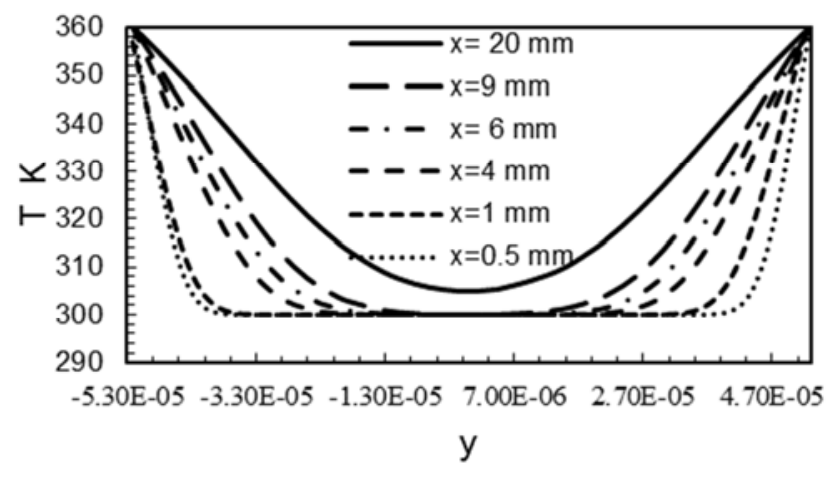

Figure 7. The temperature change in the entrance region.

The graph illustrates the variation of $\mathrm{Nu}$ number on the wall of the channel with three hydraulic diameters 106, 200 and $300 \mu \mathrm{m}$ at at constant Re number. From the Figure, it is clearly seen that the $\mathrm{Nu}$ number enhanced with the increase in the hydraulic diameter as the tested diameter $300 \mu \mathrm{m}$ showed the highest heat transfer rate among the diameters tested. The improvement in $\mathrm{Nu}$ was remarkable in the developing region as anticipated. The reason behind this is the significant temperature change in this area.

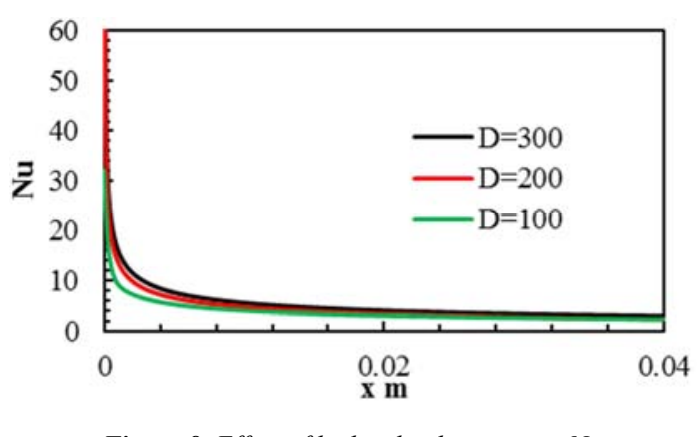

Figure 8. Effect of hydraulic diameter on $\mathrm{Nu}$.

The present study explored the velocity gradient change in the microchannel. The u-velocity gradient change in the vertical line located at the diameter of the microchannel at several locations from the flow entry is calculated, and the results are shown in Figure 9. At the fully developed region the velocity gradient becomes constant where at $\mathrm{x}=0.5 \mathrm{~mm}$, the $\mathrm{u}$-velocity gradient has the value change in the vertical line particularly near the wall. However, the value is constant far from the wall. This illustrates that the change of the velocity gradient is significant in the near wall region.

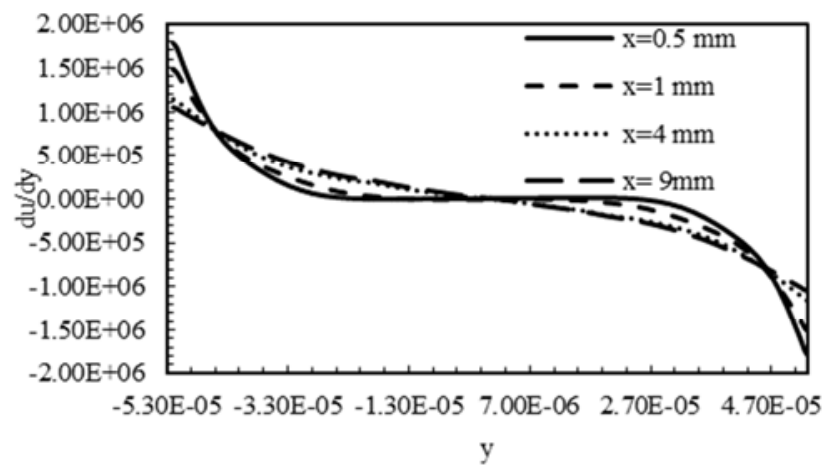

Figure 9. The velocity gradient at vertical line in the entrance region.

\section{Conclusions}

The characteristic of the flow of $\mathrm{TiO}_{2}$-water nanofluid is investigated in the present study. The change of the temperature in the microchannel and in particular in the entrance region was studied and discussed. The effect of the volume fraction on the enhancement of the heat transfer is investigated, and the increase was found in favor of the heat transfer.

The velocity variation in the entrance region was tested at various locations from the microchannel entry. The velocity gradient was also calculated, and the results were presented.

It was found that water has the lowest heat transfer performance. The increase in Re number enhanced the heat transfer rate remarkably. 
The $\mathrm{Nu}$ number improved considerably with the increase in Hydraulic diameter of the microchannel.

\section{Nomenclature}

$\begin{array}{ll}\text { A } & \text { Area }\left[\mathrm{m}^{2}\right] \\ \mathrm{k} & \text { Thermal Conductivity }\left[\mathrm{W} / \mathrm{m}^{2} \mathrm{~K}\right] \\ \mathrm{q}] & \text { Heat Flux }\left[\mathrm{W} / \mathrm{m}^{2} \mathrm{~K}\right] \\ \mathrm{Cp} & \text { Specific Heat at Constant Pressure }\left[\mathrm{Kj} \mathrm{kg}^{-1} \mathrm{~K}^{-1}\right] \\ \mathrm{Cf} & \text { Skin Friction Factor } \\ \mathrm{D} & \text { Diameter } \mathrm{m} \\ \mu & \text { Viscosity }\left[\mathrm{kg} \mathrm{m}^{-1} \mathrm{~s}^{-1}\right] \\ \rho & \text { Density }\left[\mathrm{Kg} \cdot \mathrm{m}^{-3}\right] \\ \phi & \text { Volume Fraction } \\ \mathrm{T} & \text { Temperature }[\mathrm{oK}] \\ \mathrm{h} & \text { Heat Transfer Coefficient } \\ \mathrm{L} & \text { Length }[\mathrm{m}] \\ \mathrm{Re} & \text { Reynolds Number }=\mathrm{uD} \rho / \mu \\ \mathrm{Nu} & \text { Nusselt Number }=\mathrm{hD} / \mathrm{K} \\ \mathrm{v} & \text { Velocity vector }\end{array}$

\section{References}

[1] S. U. S. Choi and J. A. Eastman, Enhancing thermal conductivity of fluids with nanoparticles, 1995.

[2] J. Koo and C. Kleinstreuer, "Laminar nanofluid flow in microheat-sinks," International Journal of Heat and Mass Transfer, vol. 48, pp. 2652-2661, 6/ 2005.

[3] J. Chevalier, O. Tillement, and F. Ayela, "Rheological properties of nanofluids flowing through microchannels," Applied Physics Letters, vol. 91, p. 233103, 2007.

[4] C. T. Nguyen and M. Le Menn, "Two-phase modeling of nanofluid heat transfer in a microchannel heat sink," vol. 1, pp. 451-460, 2009.

[5] J. Li and C. Kleinstreuer, "Entropy Generation Analysis for Nanofluid Flow in Microchannels," Journal of Heat Transfer, vol. 132 , p. $122401,2010$.

[6] R. Wälchli, T. Brunschwiler, B. Michel, and D. Poulikakos, "Combined local microchannel-scale CFD modeling and global chip scale network modeling for electronics cooling design," International Journal of Heat and Mass Transfer, vol. 53, pp. 1004-1014, 2010.

[7] M. Kalteh, A. Abbassi, M. Saffar-Avval, A. Frijns, A. Darhuber, and J. Harting, "Experimental and numerical investigation of nanofluid forced convection inside a wide microchannel heat sink," Applied Thermal Engineering, vol. 36, pp. 260-268, 4/ 2012.

[8] H. A. Mohammed, G. Bhaskaran, N. H. Shuaib, and R. Saidur, "Heat transfer and fluid flow characteristics in microchannels heat exchanger using nanofluids: A review," Renewable and Sustainable Energy Reviews, vol. 15, pp. 1502-1512, 2011.

[9] S. V. B. Vivekanand and V. R. K. Raju, "Simulation of Evaporation Heat Transfer in a Rectangular Microchannel," Procedia Engineering, vol. 127, pp. 309-316, 2015.

[10] R. Chein and G. Huang, "Analysis of microchannel heat sink performance using nanofluids," Applied Thermal Engineering, vol. 25, pp. 3104-3114, 12/ 2005.

[11] S. P. Jang and S. U. S. Choi, "Cooling performance of a microchannel heat sink with nanofluids," Applied Thermal Engineering, vol. 26, pp. 2457-2463, 12/ 2006.

[12] R. Chein and J. Chuang, "Experimental microchannel heat sink performance studies using nanofluids," International Journal of Thermal Sciences, vol. 46, pp. 57-66, 2007/01/01 2007.

[13] E. Manay and B. Sahin, "The effect of microchannel height on performance of nanofluids," International Journal of Heat and Mass Transfer, vol. 95, pp. 307-320, 4/ 2016.

[14] J. Lee and I. Mudawar, "Assessment of the effectiveness of nanofluids for single-phase and two-phase heat transfer in micro-channels," International Journal of Heat and Mass Transfer, vol. 50, pp. 452-463, 2// 2007.

[15] M. D. Byrne, R. A. Hart, and A. K. da Silva, "Experimental thermal-hydraulic evaluation of $\mathrm{CuO}$ nanofluids in microchannels at various concentrations with and without suspension enhancers," International Journal of Heat and Mass Transfer, vol. 55, pp. 2684-2691, 4// 2012.

[16] T.-C. Hung, W.-M. Yan, X.-D. Wang, and C.-Y. Chang, "Heat transfer enhancement in microchannel heat sinks using nanofluids," International Journal of Heat and Mass Transfer, vol. 55, pp. 2559-2570, 4/ 2012.

[17] J.-Y. Jung, H.-S. Oh, and H.-Y. Kwak, "Forced convective heat transfer of nanofluids in microchannels," International Journal of Heat and Mass Transfer, vol. 52, pp. 466-472, 1/15/ 2009.

[18] K. Anoop, R. Sadr, J. Yu, S. Kang, S. Jeon, and D. Banerjee, "Experimental study of forced convective heat transfer of nanofluids in a microchannel," International Communications in Heat and Mass Transfer, vol. 39, pp. 1325-1330, 11/ 2012.

[19] E. M. Tokit, H. A. Mohammed, and M. Z. Yusoff, "Thermal performance of optimized interrupted microchannel heat sink (IMCHS) using nanofluids," International Communications in Heat and Mass Transfer, vol. 39, pp. 1595-1604, 12/ 2012.

[20] T.-C. Hung and W.-M. Yan, "Enhancement of thermal performance in double-layered microchannel heat sink with nanofluids," International Journal of Heat and Mass Transfer, vol. 55 , pp. $3225-3238,5 / 2012$.

[21] A. Malvandi, S. A. Moshizi, and D. D. Ganji, "Twocomponent heterogeneous mixed convection of alumina/water nanofluid in microchannels with heat source/sink," Advanced Powder Technology, vol. 27, pp. 245-254, 1/ 2016.

[22] A. Malvandi, S. A. Moshizi, and D. D. Ganji, "Effects of temperature-dependent thermophysical properties on nanoparticle migration at mixed convection of nanofluids in vertical microchannels," Powder Technology, vol. 303, pp. 7$19,12 / 2016$

[23] J. Zhang, Y. Diao, Y. Zhao, and Y. Zhang, "Experimental study of $\mathrm{TiO}_{2}$-water nanofluid flow and heat transfer characteristics in a multiport minichannel flat tube," International Journal of Heat and Mass Transfer, vol. 79, pp. 628-638, 12/ 2014.

[24] N. R. Kuppusamy, H. A. Mohammed, and C. W. Lim, "Numerical investigation of trapezoidal grooved microchannel heat sink using nanofluids," Thermochimica Acta, vol. 573, pp. 39-56, 12/10/ 2013. 
[25] N. Alagumurthi and T. Senthilvelan, "Investigation of Heat Transfer in Serpentine Shaped Microchannel Using $\mathrm{Al}_{2} \mathrm{O}_{3}$ /Water Nanofluid," Heat Transfer-Asian Research, $45 / 2014$.

[26] S. Etaig, R. Hasan, and N. Perera, "Investigation of a New Effective Viscosity Model for Nanofluids," Procedia Engineering, vol. 157, pp. 404-413, // 2016.
[27] ANSYS Available: http://www.ansys.com/Products/Fluids/ANSYS-Fluent

[28] P.-S. Lee, S. V. Garimella, and D. Liu, "Investigation of heat transfer in rectangular microchannels," International Journal of Heat and Mass Transfer, vol. 48, pp. 1688-1704, 2005. 